\title{
Screening of the Phenolic Compound and Antioxidant Activity from Sugar Process
}

\author{
Walaiporn Rungjang ${ }^{1}$, Siriluck Liengprayoon ${ }^{2}$, \\ Jackapon Sunthornvarabhas ${ }^{3,4}$ and Klanarong Sriroth ${ }^{1,3, *}$ \\ ${ }^{I}$ Department of Biotechnology, Faculty of Agro-Industry, Kasetsart University, Bangkok 10900, Thailand \\ ${ }^{2}$ Kasetsart Agricultural and Agro-Industrial Product Improvement Institute, Kasetsart University, \\ Bangkok 10900, Thailand \\ ${ }^{3}$ Mirt Phol Group, Phu Khiao, Chaiyaphum 36100, Thailand \\ ${ }^{4}$ National Center for Genetic Engineering and Biotechnology, Pathum Thani 12120, Thailand
}

("Corresponding author’s e-mail: aapkrs@ku.ac.th, klanarongs@mitrphol.com)

Received: 20 July 2020, Revised: 10 March 2021, Accepted: 20 April 2021

\begin{abstract}
Phenolic profile and antioxidant activity of sugarcane plant parts (leaf, stem, and root), intermediate products ( $1^{\text {st }}$ juice, mixed juice, clarified juice and syrup), product (raw sugar) and by-products (molasses, bagasse, and filter cake) from sugar process were first studied from the same production line. Total phenolic content (TPC) of all samples was obtained from solvent extraction and was quantified by FolinCiocalteu (FC) method. The identification and quantification of individual phenolic compounds (PC) were performed with HPLC-DAD. The antioxidant activity of all extracted samples was determined by the DPPH method. HPLC analysis revealed that the PC of extracts was composed of chlorogenic acid, vanillic acid, caffeic acid, 4-hydroxybenzoic acid, syringic acid, and $p$-Coumaric acid. Sugarcane leaf $(1,804.15 \pm 144.34 \mathrm{mg} / \mathrm{kg}$ dry basis), molasses $(2,092.56 \pm 153.17 \mathrm{mg} / \mathrm{kg}$ dry basis $)$ and bagasse $(282.65 \pm 25.20 \mathrm{mg} / \mathrm{kg}$ dry basis) were the 3 major sources of phenolic compounds from the sugar process as quantified by HPLC-DAD. These materials also exhibited strong antioxidant activity among studied samples. The DPPH radical scavenging activity of sugarcane leaf, molasses and bagasse extracts were $92.34 \pm 0.07,91.46 \pm 0.28$, and $86.96 \pm 1.71 \%$, respectively. These results revealed that sugarcane leaf, molasses and bagasse are a potential source for further use in various applications that required antioxidant activity for supplementary foods, pharmaceuticals and cosmetics for health promotion.
\end{abstract}

Keywords: Phenolic profile, Antioxidant activity, Sugarcane, Sugar process, Phenolic compounds

\section{Introduction}

Sugarcane is one of the most important industrial crops and the only raw material for sugar production in Thailand. Sugarcane leaf, bagasse, filter cake and ash are the major by-product and currently utilize as fuel for electricity production and land preparation. Joint collaborative research between government institutes and the private sector investigated the potential application of a by-product from the sugar process $[1,2]$. During an investigation, phenolic compounds, the secondary metabolites in plants [3] were found in several parts of sugarcane and recognized as a potential source of natural phenolic compounds [4,5]. Due to its potent antioxidant activity, anti-inflammatory and anti-cancer activity, phenolic compounds are applied also used for a variety of applications especially cosmetic and pharmaceutical products [6-8]. Generally, in Thai sugar processing, a $1^{\text {st }}$ crushing machine is used to squeeze the cane to obtain " $1{ }^{\text {st }}$ juice". Then the ground canes are treated by diffusion of hot water $\left(95^{\circ} \mathrm{C}\right)$ from all crushing machines ( $1-5$ crushing machine). Sugarcane juice mixed from all the crushing machine were obtained and called "mixed juice". After the crushing step, sugarcane "bagasse" is separated and applied to generate heat and power. Mixed juice is subjected to several chemical treatments and filtrations, carbonation in the presence of lime and carbon dioxide and clarification by the addition of flocculants, to eliminate all impurities such as soil, sand, high molecular weight polysaccharides (starch, dextran) and color-forming compounds including PC, thus leading to "clarified juice". After the clarifying step, the impurities of mixed juice were separated to obtain "filter cake" which is used as a fertilizer and soil conditioner. The clarified juice was boiled by heat exchange in the evaporator, which results in a 
highly concentrated juice called "syrup". Sucrose crystallization is then achieved by the concentration of the syrup under vacuum to provide the massecuite (a mixture of sucrose and molasses). Seed crystals, a small piece of single sucrose crystals, are added to the massecuite. At the centrifugation step, sucrose is extracted from the syrup. Sucrose is separated from "molasses" by centrifugation and dried to give commercial "raw sugar".

Besides sucrose, phenolic and flavonoid are extracted during sugarcane crushing and consequently distribute along the process. From the literature, many researchers quantified and identified phenolic compounds from the sugarcane intermediate products, products and by-products from sugar process such as leaf, stem, juice, filter cake and bagasse. Tricin (flavone derivative) (11.5 mg/kg sample) [9-12] and ferulic acid (37.3 mg/kg sample) [13] were reported in the sugarcane leaf and bagasse (tricin $93 \mathrm{mg} / \mathrm{kg}$ sample [10], ferulic acid $119.73 \mathrm{mg} / \mathrm{kg}$ sample [13,14]) while chlorogenic acid (15.2 $\mathrm{mg} / \mathrm{kg}$ sample) [15] and gallic acid $(74,500 \mathrm{mg} / \mathrm{kg}$ sample) [16] were detected in the sugarcane stem. The sugarcane juice contained chlorogenic acid (30.4 mg/mL of juice) and apigenin $(7.5 \mathrm{mg} / \mathrm{mL}$ of juice [17]). Clarified juice, syrup, raw sugar and molasses contained $p$-Coumaric acid $(2.8-234.3 \mathrm{mg} / \mathrm{kg})$ and apigenin $(7.1-168.2$ $\mathrm{mg} / \mathrm{kg}$ ) [15]. The filter cake contained flavonoid and the total detected PC was $0.066 \% \mathrm{w} / \mathrm{w}$ [4]. Though certain PC such as chlorogenic acid was detected from plant parts until the products, some PC such as apigenin were found only after processing. This could be due to the fact that they were individually characterized from different sugar processes and extraction techniques, such as solvent, solid/liquid ratio and analytical techniques. In addition, the content of phenolic compounds in intermediate products and by-products were reported to be influenced by the condition of the process as some phenolic compounds were gradually eliminated at the elevated temperature and $\mathrm{pH}$ [4].

To the best of our knowledge, the complete screening of phenolic profile from a single sugar process (sugarcane plant parts, intermediate products, product, and by-products) has not been fully investigated and was unable to compare due to differences in extraction methods and conditions thus prevent a good comparison among studies. Therefore, the objectives of this study were to determine the total phenolic content of those products according to the Folin-Ciocalteu method, to identify phenolic compounds using HPLC-DAD, and also to evaluate the antioxidant activity by DPPH assay.

\section{Materials and methods}

\section{Chemicals}

Gallic acid (GA), catechin (CAT), caffeic acid (CAF), chlorogenic acid (CGA), bovine serum albumin (BSA), glucose, fructose, and sucrose were purchased from Sigma-Aldrich (St. Louis, MO, USA). Methanol (99.9\%) and Folin-Ciocalteu's phenol reagent (2 M) were purchased from Merck (Darmstadt, Germany). Bio-Rad Protein Assay Dry reagent concentrate was purchased from Bio-rad (Hercules, California, USA). The sucrose/D-glucose/D-fructose assay was purchased from Megazyme (Bray, Wicklow, Ireland). Sodium carbonate was purchased from Thermo Fisher Scientific (Scoresby, Melbourne, Australia). All the chemicals and reagents were analytical grade.

\section{Samples}

Sugarcane leaf, stem, root, $1^{\text {st }}$ juice, mixed juice, clarified juice, syrup, raw sugar, bagasse, filter cake and molasses were collected from Mitr Phol sugar factory (Suphanburi, Thailand) from the $2016 / 2017$ milling season. All samples were kept in a freezer $\left(-20{ }^{\circ} \mathrm{C}\right)$ for storage before transport from the sugar factory to Kasetsart University (Bangkok, Thailand) and for analysis.

\section{Sample preparation}

For liquid samples; the $1^{\text {st }}$ juice (FJ), mixed juice (MJ) and clarified juice (CJ) were centrifuged at $15,000 \mathrm{rpm}$ for $20 \mathrm{~min}$ at $4{ }^{\circ} \mathrm{C}$ to precipitate any particulates [7]. The supernatant was collected and preserved at $-20{ }^{\circ} \mathrm{C}$ until used. Sugar content in the solution, Brix, was determined by a refractometer. Syrup and molasses were diluted to $23^{\circ}$ Brix with distilled water to provide a sample solution with a similar concentration of sucrose as of sugarcane juice (Brix of sugarcane juice was 15 - $23 \%$ ). Raw sugar was also dissolved to $23^{\circ}$ Brix with distilled water. A volume of $150 \mathrm{~mL}$ of each liquid sample was extracted with n-butanol $(150 \mathrm{~mL})$ in a separating funnel for 3 times. The n-butanol phase was collected and evaporated in a rotary evaporator (Buchi Rotavapor R-215, Buchi, Switzerland) and the obtained crude extract was flushed with nitrogen gas and kept for further analysis.

For solid samples; leaf, stem, root, bagasse and filter cake were dried at $45{ }^{\circ} \mathrm{C}$ until the weight was constant. All samples were ground by using the blender. All solid samples were extracted twice with 80 $\%$ methanol in water with the solid: liquid ratio of $1: 10(\mathrm{w} / \mathrm{v})$ under the ultrasonic bath (Elmasonic S30H, 
Elma, Germany) at $40 \mathrm{kHz}$ for $30 \mathrm{~min}$. After filtration through filter paper, (Whatman No.1), the extracting solvent was evaporated and the obtained crude extract was flushed with nitrogen gas and kept at $-20^{\circ} \mathrm{C}$ for further analysis.

Purification of phenolic extract from sugarcane plant part, intermediate products, products and by-products using solid phase extraction

All phenolic extracts were purified by solid phase extraction (SPE) using Oasis HLB cartridge (6 cc., $200 \mathrm{mg} ; 30 \mu \mathrm{m}$ particle size; Waters, Milford, MA, USA) conditioned with $3 \mathrm{~mL}$ of methanol and equilibrated with $3 \mathrm{~mL}$ of distilled water. The interfering compound was eluted with $8 \mathrm{~mL}$ of water, then phenolic compounds were eluted with $2 \times 2 \mathrm{~mL}$ of methanol. Purified samples were filtered through a 0.45 $\mu \mathrm{m}$ PTFE membrane before injected into the HPLC instrument for analysis.

\section{Determination of the total phenolic content by Folin-Ciocalteu method}

The total phenolic content (TPC) of all extracts was measured according to the FC method [18]. A volume of $0.5 \mathrm{~mL}$ of distilled water and $0.125 \mathrm{~mL}$ of extracts or standard was added to test tubes. The Folin-Ciocalteu reagent $(0.125 \mathrm{~mL})$ was added to the solution and allowed to react for $6 \mathrm{~min}$. Then, $7 \%$ $\mathrm{w} / \mathrm{v}$ sodium carbonate solution $(1.25 \mathrm{~mL})$ and distilled water $(1 \mathrm{~mL})$ were added into a test tube. A test tube was shaken and allowed to stand for $90 \mathrm{~min}$ at room temperature $\left(25^{\circ} \mathrm{C}\right)$ to complete the reaction. The absorbance was measured by using a spectrophotometer (UV-1800, Shimadzu, Japan) at $760 \mathrm{~nm}$. Triplicate measurements were performed for comparison with standard value; gallic acid solution at different concentrations $(0-200 \mathrm{~g} / \mathrm{mL})$. TPC was expressed as grams of gallic acid equivalent (g GAE) per kilogram of dry weight for solid samples and grams of gallic acid equivalent (g GAE) per liter of liquid samples.

\section{Standard solution for HPLC-DAD quantification}

The stock solutions of each standard (chlorogenic acid, vanillic acid, caffeic acid, 4-hydroxybenzoic acid, syringic acid, and p-Coumaric acid) were prepared as follow: an accurately weighed $100 \mathrm{mg}$ of the pure compound was placed into $10 \mathrm{~mL}$ volumetric flask; methanol $(99.9 \%)$ was added and the volume of solution was adjusted with the same solvent. The standard calibration curve was generated using 10 data points, covering the concentration ranges as described in Table 1. The standard injection volume was 20 $\mu \mathrm{L}$. The injection was performed in triplicate for each concentration level. The calibration curve was obtained by plotting the peak area of the compound at each level versus the concentration of the sample. The amount of phenolic acid in sugarcane plant, intermediate products, product, and by-products extracts was quantified by using these calibration curves when the standard was available.

Table 1 Linearity for phenolic compounds used as standards for HPLC-DAD.

\begin{tabular}{lccc}
\hline \multicolumn{1}{c}{ Phenolic compound } & Linearity range $(\boldsymbol{\mu g} / \mathbf{m L})$ & Slope & $\mathbf{R}^{\mathbf{2}}$ \\
\hline Chlorogenic acid & $10-200$ & 26,752 & 0.9987 \\
Vanillic acid & $10-200$ & 16,112 & 0.9998 \\
Caffeic acid & $10-200$ & 82,813 & 0.9995 \\
4-hydroxybenzoic acid & $10-200$ & 143,352 & 0.9999 \\
Syringic acid & $10-200$ & 41,560 & 0.9997 \\
$p$-Coumaric acid & $10-200$ & 81,821 & 0.9999 \\
\hline
\end{tabular}

\section{Profiling of phenolic compound using HPLC-DAD}

HPLC-DAD analysis was performed using a Shimadzu model (CTO-20A, Shimadzu, Japan), consisting of a vacuum degasser, a quaternary pump, an autosampler, a thermostatted column compartment and a diode array detector (DAD) (SPD-M20A, Shimadzu, Japan). The separation was carried out on a Symmetry C18 column $\left(150 \times 3.9 \mathrm{~mm}^{2}\right.$ I.D., $5 \mu \mathrm{m}$, Waters $)$. The column temperature was set at $30{ }^{\circ} \mathrm{C}$. The sample injection volume was $20 \mu \mathrm{L}$. The gradient of elution was performed with (A) water and $3 \% \mathrm{v} / \mathrm{v}$ acetic acid and (B) acetonitrile with the elution profile indicated in Table 2. The flow rate of $0.8 \mathrm{~mL} / \mathrm{min}$ was used. The DAD acquisitions were performed in the range of $190-800 \mathrm{~nm}$. Data analysis was performed with LabSolutions program V5.9 (Shimadzu, Japan). For quantification, DAD chromatograms were extracted at $280 \mathrm{~nm}$ (for chlorogenic acid, vanillic acid, 4-hydroxybenzoic acid, syringing acid, and p-Coumaric acid), and $322 \mathrm{~nm}$ (for caffeic acid). Three injections were performed for each sample. 
Table 2 Elution profile used in the HPLC-DAD analysis.

\begin{tabular}{ccc}
\hline Time (min) & Mobile phase A (\%) & Mobile phase B (\%) \\
\hline 0 & 95 & 5 \\
40 & 85 & 15 \\
45 & 50 & 50 \\
50 & 30 & 70 \\
60 & 30 & 70 \\
70 & 95 & 5 \\
\hline
\end{tabular}

\section{DPPH radical scavenging assay}

DPPH free radical scavenging activity was measured to determine the antioxidant activity. Briefly, 1 $\mathrm{mL}$ of each sample solution was mixed thoroughly with $1 \mathrm{~mL}$ of $0.25 \mathrm{mM}$ DPPH solution in methanol. The concentration of the extract samples at $1 \mathrm{mg} / \mathrm{mL}$ was prepared. The solution was incubated in the room temperature $\left(25^{\circ} \mathrm{C}\right)$ for $60 \mathrm{~min}$. The control sample contained methanol instead of the compound solution, and the blank sample contained methanol in place of the DPPH solution. After incubation, the absorbance was measured at $517 \mathrm{~nm}$ using Shimadzu UV-Vis 1800 . Gallic acid $(0.001-0.020 \mathrm{mg} / \mathrm{mL})$ and catechin $(0.010-0.100 \mathrm{mg} / \mathrm{mL})$ were used as standard. The DPPH radical scavenging activity was calculated as follows:

The DPPH radical scavenging activity $(\%)=\left(\frac{A_{b}-A_{s}}{A_{b}}\right) \times 100$

Where $A_{b}$ is the absorbance of the blank sample and $A_{s}$ is the absorbance of the test extract sample.

\section{Statistical analysis}

All data were expressed as mean \pm standard deviation from a minimum of 3 replicates. Data analyses were carried out using SPSS version 15.0. Significant differences were compared using Duncan's test and a probability of $p<0.05$ was considered as a statistical difference. The linear correlation test and residual analyses were performed by simple linear regression, considering R2 equal to or higher than 0.99 to be satisfactory accurate.

\section{Results and discussion}

Screening of the total phenolic content determined by Folin-Ciocalteu method

Table 3 showed the total phenolic content (TPC) of the sugarcane plant, intermediate products, products and by-products extracts that were determined by FC methods. TPC of all extracts ranged from 0.05 to $13.25 \mathrm{~g} \mathrm{GAE} / \mathrm{kg}$ sample. Sugarcane leaf, molasses and bagasse contain TPC approximately 13.25 , 7.10 and $4.07 \mathrm{mg} \mathrm{GA} / \mathrm{kg}$ dry sample, respectively. The TPC in the root (10.91 g GAE $/ \mathrm{kg}$ sample) was higher than in comparison with sugarcane stem (1.75 g GAE/kg sample), similar to Li et al. [19]. The contents of the phenolic compound, plant defense metabolite, were higher in the root $(10.91 \mathrm{~g} \mathrm{GAE} / \mathrm{kg}$ sample). According to Table 4, the HPLC results of the detection of $p$-Coumaric acid, which was associated with lignin due to its being a basic component, were highest. Therefore, the high value of detected TPC from the root was contributed from lignin content. The high content of lignin in the root was due to lignification and resistance, which offer greater hardness, low tissue elasticity and consequent physical barrier to soil pathogens [20]. 
Table 3 Total phenolic content of sugarcane plant, intermediate products, products and by-products extracts by FC method from sugar process.

\begin{tabular}{ccc}
\hline Sample group & Sample type & TPC (g GAE/kg (L) sample) \\
\hline Plant & Leaf & $13.25 \pm 0.30^{\mathrm{a}}$ \\
& Stem & $1.75 \pm 0.04^{\mathrm{b}}$ \\
Root & $10.91 \pm 0.09^{\mathrm{c}}$ \\
& $1^{\text {st }}$ juice & $0.92 \pm 0.10^{\mathrm{d}}$ \\
& Mixed juice & $0.98 \pm 0.06^{\mathrm{d}}$ \\
Product & Clarified juice & $2.05 \pm 0.01^{\mathrm{e}}$ \\
By-products & Syrup & $1.25 \pm 0.03^{\mathrm{f}}$ \\
& Raw sugar & $0.05 \pm 0.00^{\mathrm{g}}$ \\
& Molasses & $7.10 \pm 0.47^{\mathrm{h}}$ \\
& Bagasse & $4.07 \pm 0.14^{\mathrm{i}}$ \\
& Filter cake & $0.97 \pm 0.00^{\mathrm{d}}$ \\
\hline
\end{tabular}

\section{Phenolic compound of extract from sugar process analyzed by HPLC-DAD}

Phenolic compounds in extracts were identified based on their retention times and UV-DAD spectra $(190-800 \mathrm{~nm})$. A diode-array detector set at 2 wavelengths of $280 \mathrm{~nm}$ and $322 \mathrm{~nm}$ was used to characterize and quantify the hydroxybenzoic acid (vanillic acid at $291 \mathrm{~nm}$ and 4-hydroxybenzoic acid at $280 \mathrm{~nm}$ ) and hydroxycinnamic acid (chlorogenic acid at $325 \mathrm{~nm}$, caffeic acid at $322 \mathrm{~nm}$, $p$-Coumaric acid at $309 \mathrm{~nm}$, and syringic acid at $274 \mathrm{~nm}$ ) of unknown peaks with the available reference standard.

The phenolic profile of the leaf, stem, root, $1^{\text {st }}$ juice, mixed juice, clarified juice, syrup, raw sugar, filter cake, bagasse, and molasses extract was shown in Table 4.

\section{Sugarcane plant part}

In-plant parts, phenolic acid, including hydroxycinnamic acid ( $p$-Coumaric acid, caffeic acid and chlorogenic acid) and hydroxybenzoic acid derivatives (4-hydroxybenzoic acid, syringic acid and vanillic acid), are physically dispersed throughout leaf, root and stem. A $p$-Coumaric acid and caffeic acid are native to the sugarcane plant and result from the degradation of lignin and hemicellulose material [5]. In the plant part, the types of detected phenolic compounds by HPLC in leaf, stem, and root extract samples were slightly different. The detected TPC content by HPLC of leaf extract $(1,804.15 \pm 144.34 \mathrm{mg} / \mathrm{kg}$ dry basis) was the highest compared to the stem (137.95 \pm 23.09$)$ and root $(264.91 \pm 17.42 \mathrm{mg} / \mathrm{kg}$ dry basis). Detected TPC from sugarcane leaf was caffeic acid, chlorogenic acid and $p$-Coumaric acid in similar concentrations previously reported by Zhao et al. [13]. While Li et al. [19] and Colombo et al. [21] reported that flavonoids such as luteolin, tricin, diosmin, vitexin, and orientin were found in the leaf. In the extract from sugarcane stem, vanillic acid, caffeic acid, syringic acid, and $p$-Coumaric acid were detected as previously reported by Duarte-Almeida et al. [15] and Feng et al. [16]. However, large variation in type and amount of phenolic and flavonoid in sugarcane leaf, stem, and root could be due to a factor such as sugarcane cultivars, growth condition, genotype, extraction and measurement technique.

Table 4 Content of phenolic compounds by HPLC-DAD of the sugarcane plant parts, intermediate products, product and by-product from sugar process.

\begin{tabular}{|c|c|c|c|c|c|c|c|c|c|c|c|c|}
\hline \multicolumn{2}{|c|}{$\begin{array}{l}\text { Sample type from } \\
\text { sugar process }\end{array}$} & \multicolumn{3}{|c|}{ Plant part } & \multicolumn{4}{|c|}{ Intermediate products } & \multirow{2}{*}{$\begin{array}{c}\text { Product } \\
\text { Raw sugar } \\
\text { (mg/ kg } \\
\text { dry } \\
\text { sample) }\end{array}$} & \multicolumn{3}{|c|}{ By-products } \\
\hline $\begin{array}{l}\text { Phenolic } \\
\text { compounds }\end{array}$ & $\underset{(\min )}{\mathrm{RT}}$ & $\begin{array}{c}\text { Leaf } \\
\text { (mg/ kg dry } \\
\text { sample) }\end{array}$ & $\begin{array}{c}\text { Stem } \\
\text { (mg/ kg dry } \\
\text { sample) }\end{array}$ & $\begin{array}{c}\text { Root } \\
\text { (mg/kg dry } \\
\text { sample) }\end{array}$ & $\begin{array}{c}\text { First juice } \\
\text { (mg/ kg dry } \\
\text { basis of } \\
\text { sample ) } \\
\end{array}$ & $\begin{array}{l}\text { Mixed juice } \\
\text { (mg/kg dry } \\
\text { basis of } \\
\text { sample) } \\
\end{array}$ & $\begin{array}{c}\text { Clarified } \\
\text { juice (mg/ kg } \\
\text { dry basis of } \\
\text { sample) }\end{array}$ & $\begin{array}{l}\text { Syrup (mg/ } \mathbf{~ k g} \\
\text { dry basis of } \\
\text { sample ) }\end{array}$ & & $\begin{array}{l}\text { Molasses (mg/ } \\
\text { kg dry sample ) }\end{array}$ & $\begin{array}{c}\text { Bagasse } \\
\text { (mg/kg dry } \\
\text { sample) }\end{array}$ & $\begin{array}{c}\text { Filter cake } \\
\text { (mg/ kg dry } \\
\text { sample) }\end{array}$ \\
\hline $\begin{array}{l}\text { Chlorogenic } \\
\text { acid }\end{array}$ & 9.75 & $851.82 \pm 40.87$ & ND & $33.77 \pm 0.61$ & ND & ND & ND & $86.64 \pm 0.49$ & ND & $558.95 \pm 16.03$ & $38.88 \pm 12.07$ & ND \\
\hline Vanillic acid & 10.77 & ND & $62.76 \pm 2.85$ & $42.59 \pm 4.37$ & $9.45 \pm 5.29$ & $284.71 \pm 64.51$ & $108.43 \pm 4.95$ & $351.45 \pm 30.73$ & ND & $361.09 \pm 26.23$ & $35.45 \pm 5.72$ & $7.34 \pm 1.20$ \\
\hline Caffeic acid & 11.27 & $813.45 \pm 80.62$ & $19.87 \pm 2.97$ & $30.95 \pm 1.78$ & ND & $47.76 \pm 7.05$ & ND & $96.18 \pm 0.41$ & ND & $156.21 \pm 9.36$ & $10.37 \pm 0.95$ & $2.65 \pm 0.71$ \\
\hline $\begin{array}{l}4- \\
\text { Hydroxyben } \\
\text { zoic acid }\end{array}$ & 11.41 & ND & ND & $16.44 \pm 1.57$ & ND & ND & $38.37 \pm 7.04$ & $60.81 \pm 3.93$ & ND & $\mathrm{ND}$ & $8.67 \pm 2.12$ & $7.37 \pm 0.83$ \\
\hline Syringic acid & 12.46 & ND & $19.89 \pm 15.03$ & $43.52 \pm 2.85$ & $34.98 \pm 5.70$ & $30.33 \pm 6.12$ & $120.82 \pm 6.22$ & $90.72 \pm 8.54$ & $0.77 \pm 0.56$ & $658.44 \pm 33.60$ & $10.36 \pm 1.77$ & $9.22 \pm 0.12$ \\
\hline $\begin{array}{l}p \text {-Coumaric } \\
\text { acid }\end{array}$ & 16.63 & $138.88 \pm 22.85$ & $35.44 \pm 2.25$ & $97.66 \pm 6.25$ & $30.33 \pm 2.86$ & ND & $165.70 \pm 5.24$ & $265.03 \pm 27.35$ & $2.41 \pm 0.41$ & $357.87 \pm 67.96$ & $178.93 \pm 2.56$ & $24.95 \pm 3.23$ \\
\hline $\begin{array}{l}\text { Total } \\
\text { phenolic }\end{array}$ & & $1,804.15 \pm 144.34^{\mathrm{a}}$ & $137.95 \pm 23.09^{\mathrm{b}}$ & $264.91 \pm 17.42^{\mathrm{c}}$ & $158.76 \pm 13.85^{\mathrm{d}}$ & $362.79 \pm 77.33^{\mathrm{e}}$ & $433.33 \pm 23.46^{\mathrm{f}}$ & $950.83 \pm 71.45^{\mathrm{g}}$ & $3.19 \pm 0.96^{\mathrm{h}}$ & $2,092.56 \pm 153.17^{i}$ & $282.65 \pm 25.20^{j}$ & $51.53 \pm 6.07^{\mathrm{k}}$ \\
\hline
\end{tabular}




\section{Sugar intermediate products}

In the sugar process, it was observed that total phenolic content in intermediate products $\left(1^{\text {st }}\right.$ juice, mixed juice, clarified juice, and syrup) varied across the different fractions obtained during the sugar process as shown in Table 4. The syrup contains the highest total phenolic content $(950.83 \pm 71.45 \mathrm{mg} / \mathrm{kg}$ dry basis) which was about 2.19 times higher than that of clarified juice. This could be explained by the fact that they are the concentrated products of the sugar process which allowed the accumulation of phenolic compounds. Indeed, concentrated clarified juice or syrup, has 2.76 times higher total solid content than clarified juice. It should be noted that there were several unidentified compounds in the extracts. Therefore, further characterization is required. Nevertheless, total phenolic in the sugar process showed the same trend as compared to total phenolic reported in other studies $[5,17]$. Phenolic profiles of sugar intermediate products showed the presence of phenolic acid similar to Payet et al. [5].

\section{Sugar product and by-products}

For sugar products, raw sugar has the lowest total phenolic of $3.19 \pm 0.96 \mathrm{mg} / \mathrm{kg}$ dry basis. A syringic acid and $p$-Coumaric acid were found in raw sugar. This result is in agreement with the data of Payet et al. [5] and Duarte-Almeida et al. [15] as shown in Table 4.

For by-products, the total phenolic of filter cake extract was $51.53 \pm 6.07 \mathrm{mg} / \mathrm{kg}$ dry basis. Phenolic compounds detected from filter cake extract were vanillic acid, caffeic acid, 4-hydroxybenzoic acid, syringic acid, and $p$-Coumaric acid as shown in Table 4. Nevertheless, Li et al. [4] reported filter cake extract contained also flavonoid and anthocyanin in small content of $0.55 \mathrm{mg}$ flavonoid $/ \mathrm{g}$ sample and 0.11 $\mathrm{mg}$ anthocyanin/g sample, respectively.

For bagasse, phenolic compounds found in bagasse extract were chlorogenic acid, vanillic acid, caffeic acid, 4-hydroxybenzoic acid, syringic acid, and $p$-Coumaric acid. The total phenolic of sugarcane bagasse extracts was $282.65 \pm 25.20 \mathrm{mg} / \mathrm{kg}$ on a dry basis. As seen from Table 4, the main phenolic compounds from bagasse were $p$-Coumaric acid $(178.93 \pm 2.56 \mathrm{mg} / \mathrm{kg}$ dry basis).

For molasses, the total phenolic of molasses extracts has a $2,092.56 \pm 153.17 \mathrm{mg} / \mathrm{kg}$ dry basis. The major phenolic compounds of molasses were syringic acid $658.44 \pm 33.60 \mathrm{mg} / \mathrm{kg}$ on a dry basis and chlorogenic acid $558.95 \pm 16.03 \mathrm{mg} / \mathrm{kg}$ dry basis similar to Duarte-Almeida et al. [8] and [15]. Moreover, Duarte-Almeida et al. [15] reported molasses extracts contained flavonoid $36.40 \pm 0.50 \mathrm{mg} / 100 \mathrm{~g}$. Chlorogenic acid involved in the enzymatic browning of sugarcane juice. The content of hydroxybenzoic acid derivative (such as syringic acid) increases during the sugar process due to the degradation of hydroxycinnamic acid derivative (such as $p$-Coumaric acid, caffeic acid and chlorogenic acid) as exhibited by the presence of benzoic acid from the crystallization step [5].

The total phenolic content profile from sugar process

Figure 1A showed the total phenolic content profile from the sugar process was quantified by using the FC method. The summary of the total phenolic content of input material, leaf, stem and root, was $25.91 \mathrm{~g} \mathrm{GAE} / \mathrm{kg}$ sample. The output material, bagasse, filter cake, molasses and raw sugar, were $12.19 \mathrm{~g}$ GAE $/ \mathrm{kg}$ sample. The summary of the total phenolic content of output materials contained 2.13 times less than input materials. It is due to the influences of the sugar process that includes heating, clarifying and evaporating on the total phenolic content. Phenolic compounds may degrade during the process. As the temperature and $\mathrm{pH}$ value increase, the phenolic content decreases [4]. 


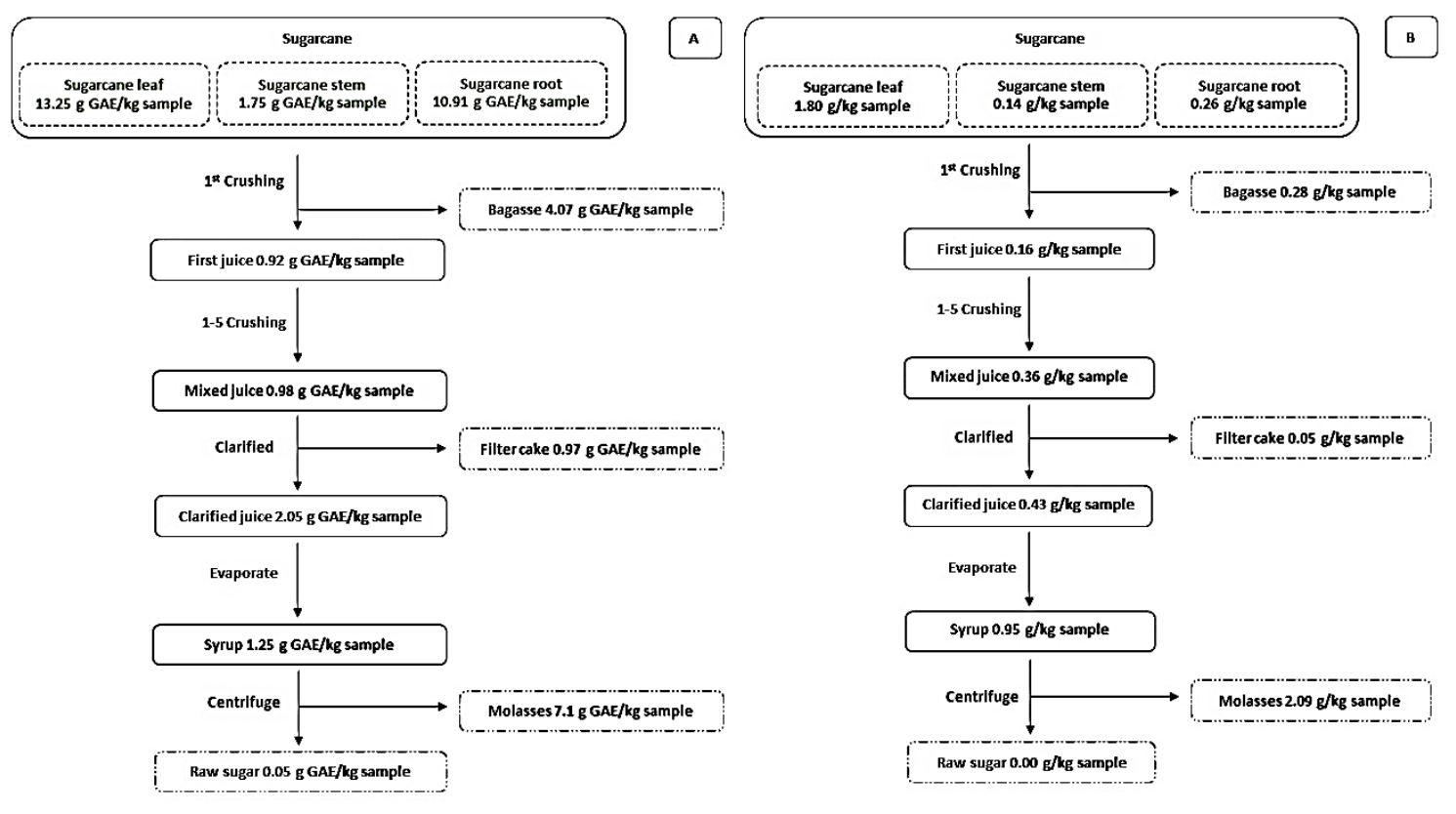

Figure 1 The total Phenolic content profile from sugarcane process obtained by FC method (A) and HPLC-DAD (B).

Figure 1B showed the total phenolic content profile from the sugar process was quantified and identified by using HPLC-DAD. The chart showed the summary of the total phenolic content of output material ( $2.42 \mathrm{~g} / \mathrm{kg}$ sample), bagasse, filter cake, molasses and raw sugar, was higher than input material $(2.20 \mathrm{~g} / \mathrm{kg}$ sample), leaf, stem and root, approximately $0.20 \mathrm{~g} / \mathrm{kg}$ sample. It may be due to the limited the phenolic standard of HPLC analysis. The phenolic compound typically found in sugarcane leaf, stem and root were not the same as molasses, bagasse and filter cake (Table 4). However, vanillic acid and syringic acid were not found in the sugarcane leaf and chlorogenic acid was not found in the stem. Otherwise, the molasses, bagasse and filter cake were found chlorogenic acid, vanillic acid and syringic acid. This was probably due to the degradation of hydroxycinnamic acid derivatives then the content of hydroxybenzoic acid increased during the process. This result is in agreement with the data of Duarte-Almeida et al. [15]. However, there were other phenolic or non-phenolic compounds present in sugarcane extracts, which need to be further studied.

Antioxidant activity of sugarcane plant part, intermediate products, products and byproducts from the sugar process

Figure 2 presents the DPPH radical scavenging activity of extracts; plant parts, intermediate products, product and by-products from sugar process and standard phenolic compound, gallic acid and catechin. These extracts activity can be divided into 3 groups which are classified by level of the DPPH radical scavenging activity; above $80 \%$ as high level, between 30 to $80 \%$ as moderate level and below $30 \%$ as low level. 


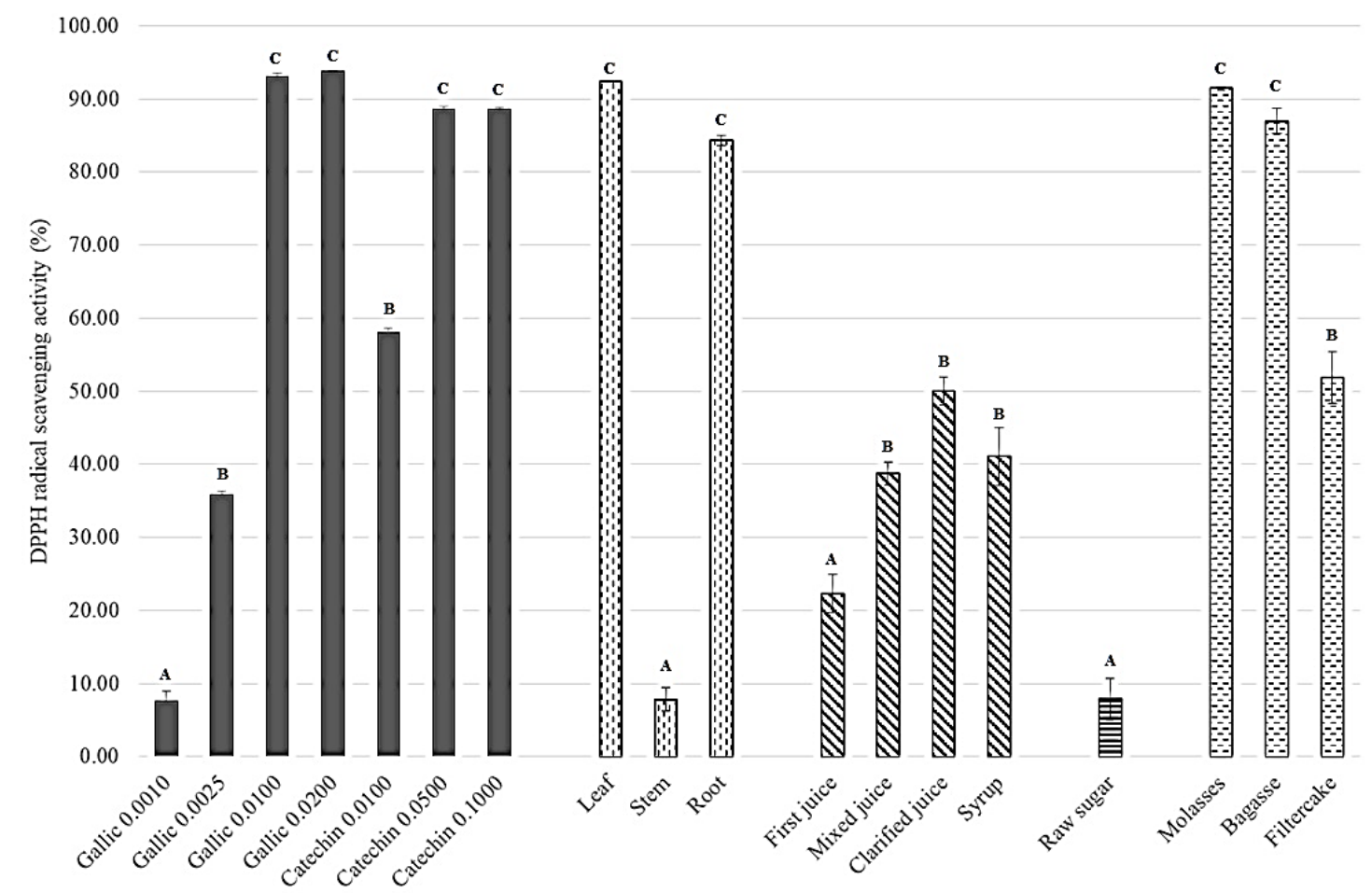

Figure 2 The DPPH radical scavenging activity (\%) value by DPPH method of sugarcane plant parts, intermediate products, product and by-products extracts from sugar process.

The $1^{\text {st }}$ group, a high level of the DPPH radical scavenging activity, consists of extracts from leaf, root, molasses and bagasse. The phenolic compounds from these materials exhibit high the DPPH radical scavenging activity as compare to standard phenolic compounds, gallic acid and catechin at 0.0100 and $0.0500 \mathrm{mg} / \mathrm{mL}$, respectively. A similar result was found in sugarcane leaf extracts by Abbas et al. [6] who reported sugarcane leaf extract exhibited a high-level antioxidant activity by the DPPH method. DuarteAlmeida et al. [15] reported molasses extract has high phenolic content $(29.45 \pm 2.54 \mathrm{mg} / 100 \mathrm{~g})$ and also antioxidant activity (45.2\% inhibition by DPPH method) similar to this study.

The $2^{\text {nd }}$ group, a moderate level of the DPPH radical scavenging activity, including extracts from $1^{\text {st }}$ juice, mixed juice, clarified juice, syrup and filter cake, could be compared to gallic acid and catechin at 0.0025 and $0.0100 \mathrm{mg} / \mathrm{mL}$, respectively.

The $3^{\text {rd }}$ group, a low level of the DPPH radical scavenging activity, consists of a stem and raw sugar. Extracts from these materials contain the phenolic compounds that have lowest the DPPH radical scavenging activity and could be compared to gallic acid at $0.0010 \mathrm{mg} / \mathrm{mL}$.

Comparison of the DPPH radical scavenging activity of the standard phenolic compound, gallic acid was higher than catechin at the same concentration $(0.01 \mathrm{mg} / \mathrm{mL})$. Due to the chemical structure of gallic acid and catechin. The phenolic compound contains an aromatic ring with $-\mathrm{OH}$ substitutes which together contribute to their biological activity, including antioxidant action [22]. The DPPH radical scavenging mechanism of phenolic acid (gallic acid) is depending on the degree of hydroxyl group [3]. While flavonoid (catechin), the DPPH radical scavenging mechanism is thought to be hydrogen atom donation and the structure requirements include an ortho-dihydroxy substitution in the $\mathrm{B}$ ring, a $\mathrm{C} 2=\mathrm{C} 3$ double bond and $\mathrm{C} 4$ carbonyl group in the $\mathrm{C}$ ring. The free hydroxyl groups on the $\mathrm{B}$ ring donate hydrogen to a radical, thus stabilizing it and giving rise to a relatively stable flavonoid radical [22]. 


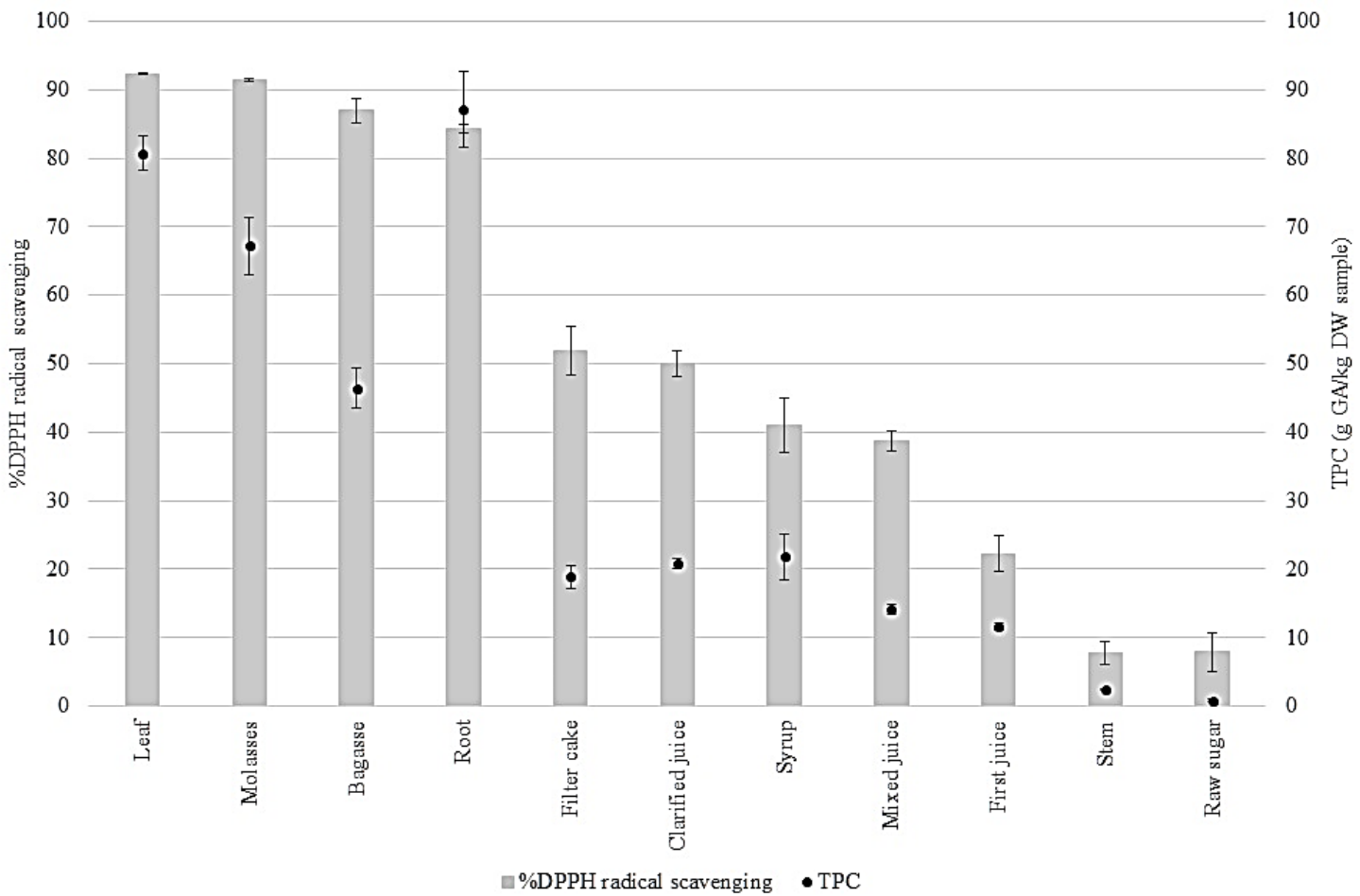

Figure 3 The relation of the DPPH radical scavenging and total phenolic content of sugarcane plant parts, intermediate products, products and by-products extracts from the sugar process.

Figure 3 showed a correlation $(\mathrm{R}=0.837)$ between the TPC and the DPPH radical scavenging in each extract. The DPPH radical scavenging activity of leaf, molasses and bagasse was observed that the high DPPH radical scavenging activity value (an increase in free radical scavenging activity) of extracts is in agreement with the TPC and confirm the usual correlation between TPC and antioxidant activity [23]. The DPPH radical scavenging activity of each extract might be mostly related to their concentration of phenolic hydroxyl group in each sample. The antiradical activity of phenolic compound depends on their molecular structure, that is, on the availability of phenolic hydrogens and the possibility for stabilization of the resulting phenoxyl radicals formed by hydrogen donation [24].

The result of this study indicated that the sugarcane plant and by-products from the sugar process are a rich source of phenolic compounds and antioxidants especially, leaf, molasses and bagasse. However, root extract showed the total phenolic content higher than bagasse by twice but it was not suitable to collect because sugarcane root is usually used as a sugarcane shoot for the next cultivation season. Therefore, leaf, molasses and bagasse extract may be used as a high added-value natural bioactive material use for food, pharmaceutical and cosmetic application.

\section{Conclusions}

Phenolic profiles of a sugarcane plant part, intermediate products, product, and by-products from the sugar process were defined by HPLC-DAD and based on 6 major phenolic compounds; chlorogenic acid, vanillic acid, caffeic acid, 4-hydroxybenzoic acid, syringic acid, and $p$-Coumaric acid. The detected total phenolic compounds by HPLC of sugarcane leaf $(1,804.15 \mathrm{mg} / \mathrm{kg}$ dry basis), molasses $(2,092.56$ $\mathrm{mg} / \mathrm{kg}$ dry basis) and bagasse $(282.65 \mathrm{mg} / \mathrm{kg}$ dry basis) were 3 sources with the highest content of phenolic compound from the sugar process. The present study indicated that the antioxidant activity of these extracts was correlated with their phenolic content. The large amounts of phenolic which contribute to its higher hydroxyl radical scavenging ability. Therefore, the high phenolic compound and antioxidant activity of these materials open a new way to develop their use for supplementary foods, a functional food ingredient, pharmaceuticals, cosmetics for health promotion or in other applications that should be explored. 


\section{Acknowledgements}

This research was supported by Research and Researcher for Industry (RRi) and Mitr Phol Sugarcane Research Center, scholarship ID PHD58I0022.

\section{References}

[1] K Sriroth, W Vanichsriratana and J Sunthornvarabhas. The current status of sugar industry and byproducts in Thailand. Sugar Tech. 2016; 18, 576-82.

[2] K Sriroth and J Sunthornvarabhas. Lignin from sugar process as natural antimicrobial agent. Biochem. Pharmacol. 2018; 7, 1-4.

[3] N Balasundram, K Sundram and S Samman. Phenolic compounds in plants and agri-industrial byproducts: Antioxidant activity, occurrence, and potential uses. Food Chem. 2006; 99, 191-203.

[4] X Li, H Song, S Yao, C Jia, Y Yang and W Zhu. Quantitative analysis and recovery optimisation of flavonoids and anthocyanins in sugar-making process of sugarcane industry. Food Chem. 2011; 125, 150-7.

[5] B Payet, A Shum Cheong Sing and J Smadja. Comparison of the concentrations of phenolic constituents in cane sugar manufacturing products with their antioxidant activities. J. Agric. Food Chem. 2006; 54, 7270-6.

[6] SR Abbas, SM Sabir, SD Ahmad, AA Boligon and ML Athayde. Phenolic profile, antioxidant potential and DNA damage protecting activity of sugarcane (Saccharum officinarum). Food Chem. 2014; 147, 10-6.

[7] US Kadam, SB Ghosh, S De, P Suprasanna, TPA Devasagayam and VA Bapat. Antioxidant activity in sugarcane juice and its protective role against radiation induced DNA damage. Food Chem. 2008; 106, 1154-60.

[8] JM Duarte-Almeida, G Negri, A Salatino, JE de Carvalho and FM Lajolo. Antiproliferative and antioxidant activities of a tricin acylated glycoside from sugarcane (Saccharum officinarum) juice. Phytochemistry. 2007; 68, 1165-71.

[9] R Colombo, JH Yariwake, EF Queiroz, K Ndjoko and K Hostettmann. On-line identification of sugarcane (Saccharum officinarum L.) methoxyflavones by liquid chromatography-UV detection using post-column derivatization and liquid chromatography-mass spectrometry. J. Chromatogr. A 2005; 1082, 51-9.

[10] R Colombo, FM Lancas and JH Yariwake. Determination of flavonoids in cultivated sugarcane leaves, bagasse, juice and in transgenic sugarcane by liquid chromatography-UV detection. $J$. Chromatogr. A. 2006; 1103, 118-24.

[11] R Colombo, JH Yariwake and M McCullagh. J. Braz. Chem. Soc. 2008; 19, 483-90.

[12] R Colombo R, JH Yariwake, EF Queiroz, K Ndjoko and K Hostettmann. LC-MS/MS analysis of sugarcane extracts and differentiation of monosaccharides moieties of flavone C-glycosides. J. Liq. Chromatogr. Relat. Technol. 2013; 36, 239-48.

[13] ZG Zhao, LC Zhu, SJ Yu, X Fu and XA Zeng. Simultaneous determination of ten major phenolic acids in sugarcane by a reversed phase HPLC method. Zuckerindustrie 2008; 133, 503-7.

[14] F Xu, RC Sun, JX Sun, CF Liu, BH He and JS Fan. Determination of cell wall ferulic and $p$ Coumaric acids in sugarcane bagasse. Anal. Chim. Acta. 2005; 552, 207-17.

[15] JM Duarte-Almeida, A Salatino, MI Genovese and FM Lajolo. Phenolic composition and antioxidant activity of culms and sugarcane (Saccharum officinarum L.) products. Food Chem. 2011; 125, 660-4.

[16] S Feng, Z Luo, B Tao and C Chen. Ultrasonic-assisted extraction and purification of phenolic compounds from sugarcane (Saccharum officinarum L.) rinds. J. Food Sci. Technol. 2015; 60, 970-6.

[17] JM Duarte-Almeida, AV Novoa, AF Linares, FM Lajolo and MI Genovese. Antioxidant activity of phenolics compounds from sugar cane (Saccharum officinarum L.) juice. Plant Food Hum. Nutr. 2006; 61, 187-92.

[18] K Wolfe, X Wu and RH Liu. Antioxidant activity of apple peels. J. Agric. Food Chem. 2003; 51, 609-14.

[19] X Li, S Yao, B Tu, X Li, C Jia and H Song. Determination and comparison of flavonoids and anthocyanins in Chinese sugarcane tips, stems, roots and leaves. J. Sep. Sci. 2010; 33, 1216-23.

[20] RG Dores, SF Guimarães, TV Braga, MC Fonseca, PM Martins and TC Ferreira. Phenolic compounds, flavonoids and antioxidant activity of leaves, flowers and roots of white-weed. Hortic. Bras. 2014; 32, 486-90.

[21] R Colombo R, JH Yariwake, EF Queiroz, K Ndjoko and K Hostettmann. On-line identification of further flavone C- and O-glycosides from sugarcane (Saccharum officinarum L., Gramineae) by HPLC-UV-MS. Phytochem. Anal. 2006; 17, 337-43. 
[22] F Van de Velde, MH Grace, D Esposito, ME Pirovani and MA Lila. Quantitative comparison of phytochemical profile, antioxidant, and anti-inflammatory properties of blackberry fruits adapted to Argentina. J. Food Compost. Anal. 2016; 47, 82-91.

[23] S Feng, Z Luo, Y Zhang, Z Zhong and B Lu. Phytochemical contents and antioxidant capacities of different parts of two sugarcane (Saccharum officinarum L.) cultivars. Food Chem. 2014; 151, 452-8.

[24] YH Pyo, TC Lee, L Logendra and RT Rosen. Antioxidant activity and phenolic compounds of Swiss chard (Beta vulgaris subspecies cycla) extracts. Food Chem. 2004; 85, 19-26. 